\title{
REVIEW ARTICLE OPEN \\ Late-onset dementia: a mosaic of prototypical pathologies modifiable by diet and lifestyle
}

Mark P Mattson ${ }^{1,2}$

Idiopathic late-onset dementia (ILOD) describes impairments of memory, reasoning and/or social abilities in the elderly that compromise their daily functioning. Dementia occurs in several major prototypical neurodegenerative disorders that are currently defined by neuropathological criteria, most notably Alzheimer's disease (AD), Lewy body dementia (LBD), frontotemporal dementia (FTD) and hippocampal sclerosis of aging (HSA). However, people who die with ILOD commonly exhibit mixed pathologies that vary within and between brain regions. Indeed, many patients diagnosed with probable AD exhibit only modest amounts of disease-defining amyloid $\beta$-peptide plaques and p-Tau tangles, and may have features of FTD (TDP-43 inclusions), Parkinson's disease (a-synuclein accumulation), HSA and vascular lesions. Here I argue that this 'mosaic neuropathological landscape' is the result of commonalities in aging-related processes that render neurons vulnerable to the entire spectrum of ILODs. In this view, all ILODs involve deficits in neuronal energy metabolism, neurotrophic signaling and adaptive cellular stress responses, and associated dysregulation of neuronal calcium handling and autophagy. Although this mosaic of neuropathologies and underlying mechanisms poses major hurdles for development of disease-specific therapeutic interventions, it also suggests that certain interventions would be beneficial for all ILODs. Indeed, emerging evidence suggests that the brain can be protected against ILOD by lifelong intermittent physiological challenges including exercise, energy restriction and intellectual endeavors; these interventions enhance cellular stress resistance and facilitate neuroplasticity. There is also therapeutic potential for interventions that bolster neuronal bioenergetics and/or activate one or more adaptive cellular stress response pathways in brain cells. A wider appreciation that all ILODs share age-related cellular and molecular alterations upstream of aggregated protein lesions, and that these upstream events can be mitigated, may lead to implementation of novel intervention strategies aimed at reversing the rising tide of ILODs.

npj Aging and Mechanisms of Disease (2015) 1, 15003; doi:10.1038/npjamd.2015.3; published online 28 September 2015

\section{HISTOPATHOLOGICAL LANDSCAPES OF PROTOTYPICAL DEMENTIAS}

The brain regions that suffer the greatest amount of synapse loss and neuronal death in ILOD include the hippocampus, entorhinal cortex, medial temporal lobe, frontal cortex and inferior parietal cortex. However, the amount of neurodegeneration varies considerably between brain regions and among individuals, which may explain, in part, the inter-individual variability in the type and magnitude of deficits in different cognitive domains. ${ }^{1-3}$ Neurons that degenerate often exhibit accumulations of aggregated proteins that form fibrillar or more amorphous inclusions within their cell bodies and neurites, and/or form extracellular deposits of aggregated proteins. Together with an understanding of the genetic causes of rare cases of Alzheimer's disease (AD), Parkinson's disease (PD) and FTD, the specific proteins that accumulate within or outside of cells in the affected brain regions have been used to classify some ILODs as specific diseases. For example, a diagnosis of $A D$ is ultimately established by semiquantitative analysis of neurofibrillary tangles (comprised of hyperphosphorylated Tau protein; $\mathrm{p}$-Tau) and the density of large extracellular aggregates of amyloid $\beta$-peptide $(A \beta)$ that form amyloid plaques. Mutations in the $\beta$-amyloid precursor protein (APP) and presenilin 1 that cause early-onset familial AD result in increased production of aggregation-prone neurotoxic forms of
$A \beta$, neurofibrillary tangle formation and associated neuronal death. ${ }^{4}$ However, whereas in late-onset $A D$ the amyloid and $\mathrm{p}$-Tau pathologies occur predominantly in cerebral cortical regions, in familial $A D$ subcortical structures such as the striatum are also often severely affected. ${ }^{5}$ In this section, I describe key histopathological criteria used to assign a specific/prototypical disease diagnosis to ILOD patients, and also briefly summarize genetic aberrancies that are known to cause familial early-onset dementias. As there exists an immense literature on these disorders, I reference mainly review articles in which key original research articles are cited.

\begin{abstract}
Alzheimer's disease
A diagnosis of $A D$ requires that the patient has a clinical history of progressive memory impairment and exhibits two defining histopathological features of $A D$, the presence of abundant extracellular $A \beta$ plaques that often exhibit dystrophic neurites (neuritic plaques), and intraneuronal fibrillar aggregates of $p$-Tau (neurofibrillary tangles) (Figure 1a,b). The severity of the $A \beta$ plaque pathology is ranked from minimal (Thal stage 1) to severe (Thal stage 5), and the neurofibrillary tangle pathology is ranked on a 6-point scale from minimal (Braak stage I) to severe (Braak stage Vl). ${ }^{6}$ However, many cognitively normal elderly subjects
\end{abstract}

\footnotetext{
${ }^{1}$ Laboratory of Neurosciences, National Institute on Aging Intramural Research Program, Baltimore, MD, USA and ${ }^{2}$ Department of Neuroscience, Johns Hopkins University School of Medicine, Baltimore, MD, USA.

Correspondence: MP Mattson (mark.mattson@nih.gov)

Received 27 February 2015; revised 4 June 2015; accepted 6 July 2015
} 


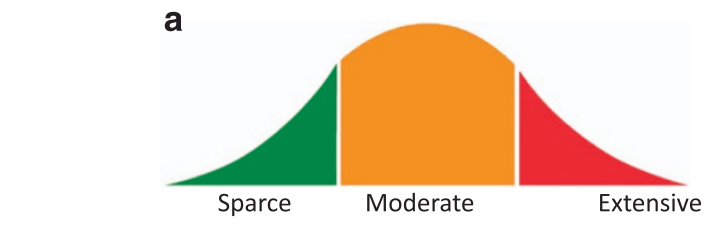

b
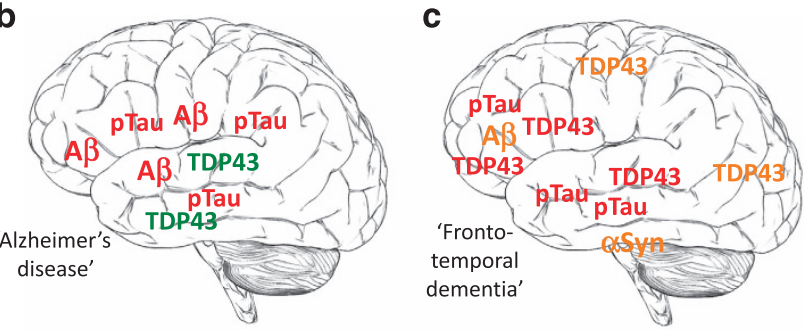

d
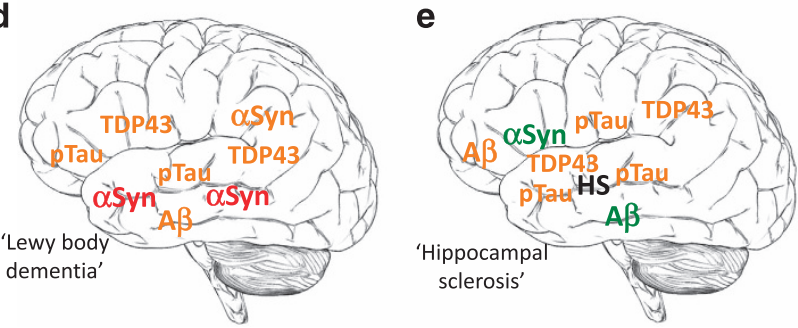

Figure 1. Each case of idiopathic late-onset dementia is a unique mosaic of prototypical neuropathological landscapes. (a) Among individuals with idiopathic late-onset dementia (ILOD) there are variable amounts of proteopathic protein aggregates from absent/sparse (green) to moderate (orange) to extensive (red): amyloid $\beta$-peptide $(A \beta)$, hyperphosphorylated Tau (pTau), TDP-43 (TDP43) and $\alpha$-synuclein ( $\alpha$ Syn). (b-e) Examples of neuropathological landscapes of four different patients with ILOD. (b) This patient exhibits robust Alzheimer's disease pathology in the temporal, frontal and inferior parietal cortices with extensive $A \beta$ and pTau pathologies. (c) This case is dominated by TDP-43 and p-Tau pathologies in the frontal and temporal lobes, with lesser amounts of TDP-43 in sensory and motor regions of the cerebral cortex, and moderate amounts of $\alpha$-synuclein in the brainstem. (d) This patient exhibits prominent Lewy body ( $\alpha$-synuclein) pathology and moderate amounts of $A \beta$ and pTau pathologies. (e) In some cases of ILOD there are low to moderate amounts of each of the four pathogenic proteins in the temporal, frontal and inferior parietal cortices, and extensive hippocampal sclerosis (HS).

harbor as much amyloid pathology as AD patients, ${ }^{7}$ suggesting that their neurons are able to withstand the neurotoxic effects of $A \beta$.

Studies of families in which early-onset $A D$ is inherited in an autosomal dominant manner have identified three genes that harbor genetic aberrancies, namely, presenilin 1, presenilin 2 and the $\beta$-APP. ${ }^{4}$ These mutations accelerate $A \beta$ accumulation by altering enzymatic processing of APP, and evidence suggests that the mutations also result in dysregulation of neuronal calcium handling, which may render neurons vulnerable to age-related oxidative stress and metabolic deficits. ${ }^{8}$ Subjects with familial AD may live for 40-50 years without evidence of cognitive impairment, indicating that, even with a disease-causing mutation, the underlying neuropathological alterations evolve over an extended time period. However, familial AD accounts for a very small percentage of all cases of $A D$ and it is as yet unclear whether altered proteolytic processing of APP is a pivotal early event or a later 'disease-accelerating' event in the common cases of sporadic $A D$. Beyond disease-causing mutations, there is one established genetic risk factor (ApoE 4) and several candidate genetic risk factors for AD. ${ }^{4}$

\section{Frontotemporal dementia}

Some inherited cases of FTD are caused by mutations in the gene encoding Tau. While progressive dementia occurs in FTD, many patients first present with psychiatric symptoms such as apathy, impulsive behavior and aggressiveness. Motor dysfunction similar to PD also occurs in many FTD patients. Cognitive symptoms include attention deficits and executive dysfunction. There is considerable inter-individual variability in the clinical presentation of FTD patients, even within the same family. ${ }^{9}$ The histopathological features of FTD are dominated by intraneuronal accumulation of $\mathrm{p}$-Tau amorphous aggregates and filaments. There is little or no $A \beta$ pathology in FTD (Figure 1c). The $p$-Tau pathology is usually confined to the cerebral cortex gray matter and white matter. Atrophy of the frontal and temporal lobes is severe. Mutations in the gene encoding transactive response DNA-binding protein 43 (TDP-43) cause some cases of FTD, ${ }^{10}$ and cytoplasmic inclusions containing phosphorylated and ubiquitinated forms of TDP-43 are prominent in FTD. ${ }^{10}$ Recently, it was found that hexanucleotide repeat expansions in C9ORF72 (a non-coding region on chromosome 9) are responsible for many cases of inherited and sporadic FTD and amyotrophic lateral sclerosis. ${ }^{11}$ TDP-43 pathology is a prominent feature in patients with C9ORF72 hexanucleotide repeat expansions. In addition, recent findings suggest that the C9ORF72 hexanucleotide repeat DNA is transcribed and the mRNA is translated into dipeptide repeat proteins that aggregate and can be neurotoxic. ${ }^{12}$

\section{Hippocampal sclerosis of aging}

Progressive atrophy of the hippocampus is a common feature of $A D$ that is associated with cognitive decline. However, many subjects with extensive hippocampal atrophy, and who are clinically indistinguishable from $A D$ patients, exhibit only minimal $A \beta$ plaque and $p$-Tau pathologies. Instead these patients suffer massive neuronal loss and gliosis in the CA1 region of the hippocampus and the adjacent subiculum, the defining pathology of HSA. ${ }^{13}$ HSA is most common in patients over the age of 80 , affecting $>20 \%$ of those diagnosed with probable AD. While $A \beta$ plaque and $p$-Tau pathologies are not prominent in HSA, TDP-43 pathology is common, with TDP-43 cytoplasmic inclusions occurring in neurons and astrocytes of the hippocampus and associated neocortical regions in the frontal and temporal lobes, and the amygdala.

The genetics of HSA is largely unexplored. Families with Mendelian inheritance of HSA have not been reported. However, recent studies have associated single-nucleotide polymorphisms in genes that encode the mitochondrial potassium channel protein $A B C C 9$, the growth factor-like glycoprotein progranulin and the lysosome/autophagy-associated protein TMEM106B with increased risk of HSA. ${ }^{14-16}$ These findings suggest that alterations in the regulation of neuronal excitability, neurotrophic support and lysosome function contribute to the pathogenesis of HSA, consistent with the notion that all ILODs involve impaired neuronal energy metabolism, neurotrophic signaling, calcium handling and autophagy.

\section{LBD and PD dementia}

The symptoms of patients with LBD include cognitive impairment, hallucinations, depression, intermittent confusion and PD-like motor signs (bradykinesia, rigidity and myoclonus). Aggregates of a-synuclein in the cytoplasm of neurons throughout the cerebral cortex and subcortical structures is the characteristic histopathological feature of LBD17 (Figure 1d). In some neurons the a-synuclein aggregates completely fill the cytoplasm of the cell body (so-called 'Lewy bodies'), whereas in other neurons smaller granular aggregates are evident. Notably, a-synuclein aggregates are also evident in axon terminals where they may 
compromise synaptic function. Mutations in the genes encoding a-synuclein and glucocerebrosidase can cause rare cases of LBD. ${ }^{18}$

Up to $75 \%$ of PD patients will develop clinical dementia, which typically occurs after the onset of autonomic and motor symptoms. Compared with age-matched control subjects, and dementia-free PD patients, PD patients with dementia exhibit cortical atrophy, white matter abnormalities and elevated amounts of $A \beta$ pathology. ${ }^{19}$ Major advances in understanding the pathogenesis of PD have come from geneticists and neuroscientists who have identified and characterized several prominent mutations that cause PD. ${ }^{20}$ Autosomal dominant PD has been linked to mutations in a-synuclein, leucine-rich repeat kinase 2 and vacuolar protein sorting-associated protein 35 (VPS35). Autosomal recessive causes of PD include mutations in the genes encoding Parkin, phosphatase and tensin homolog (PTEN)-induced kinase 1 (PINK1), DJ1 and ATP13A2. Remarkably, accrued knowledge of the apparent normal functions of these proteins and the impact of the PD causal mutations on neurons provides convincing evidence that neuronal degeneration in PD involves impaired mitochondrial bioenergetics and a compromised ability of neurons to remove a-synuclein via proteasomeand lysosome-mediated mechanisms. The centrality of mitochondrial dysfunction in PD is underscored by the fact that mitochondrial toxins can cause selective degeneration of dopaminergic neurons and associated motor symptoms that are very similar to inherited and idiopathic PD. ${ }^{21}$

\section{MOSAIC NEUROPATHOLOGICAL LANDSCAPES ARE COMMON IN ILOD}

The heterogeneity of the neuropathological landscape of ILOD is now widely appreciated and described in the literature. ${ }^{2,22-25}$ The presence of specific aggregated and posttranslationally modified (hyperphosphorylated and poly-ubiquitinated) proteins has been used to classify the cellular pathology of ILOD with the intention of labeling individual patients with a disease diagnosis. Early molecular genetic studies of AD, PD and FTD provided justification for the latter approach because APP mutations can cause dementia, $a$-synuclein mutations can cause PD and Tau mutations can cause FTD; the affected individuals exhibit predominantly $A \beta$, a-synuclein and Tau pathologies, respectively. However, many or perhaps most cases of ILOD are not readily placed within an $A D, P D$ or FTD 'disease bin'. Instead, there is a mosaic of histopathological phenotypes among ILOD patients (Figure 1). For example, in some cases, TDP-43 inclusions and HSA may be robust, with $A \beta$ and $p$-Tau pathologies minimal. Other ILOD patients with a similar cognitive deficit profile may have abundant neuritic plaques and neurofibrillary tangles in the entorhinal cortex, hippocampus and inferior parietal cortex, and so are given a diagnosis of $A D$. Patients with LBD often exhibit hippocampal sclerosis and TDP-43 inclusions in hippocampal neurons. ${ }^{26}$ In one study of 342 subjects diagnosed with $A D$ based on $A \beta$ and $p$-Tau pathology, 195 of the subjects exhibited TDP-43 pathology. ${ }^{23}$ In the latter study, TDP-43 pathology was strongly correlated with cognitive impairment and medial temporal lobe atrophy.

The blurring of the lines between what had once been considered discrete diseases is further emphasized by the existence of inherited cases of ILOD caused by mutations in the same gene, but exhibiting distinct neuropathological landscapes. For example, whereas most APP mutations that cause familial AD exhibit robust $A \beta$ plaques and $p$-Tau tangles in hippocampus, entorhinal cortex, and frontal and temporal lobes, members of a family with an APP V717l mutation exhibited extensive a-synuclein Lewy body pathology in some regions of neocortex and the substantia nigra. ${ }^{27}$ Interestingly, affected members of the latter family also exhibited robust $A \beta$ and $p$-Tau pathology in the primary visual cortex, a brain region not usually affected in AD. Some presenilin 1 mutations also result in a mixed pathology with features of both $A D$ and $P D$, often with distributions not typical of late-onset $A D$ and ILODs. For example, affected members of a family with the presenilin 1 S170F mutation developed dementia in their third decade of life and, in addition to classic $A D$ pathology, they exhibited Lewy bodies in the brainstem, limbic structures and neocortex. ${ }^{28}$ The mixed neuropathologies among subjects with different mutations in the same gene strongly suggest that other genetic factors and environmental factors impact the disease process.

In ILOD, advancing age is the major risk factor and provides a progressively unfavorable environment within the brain, and evidence from studies of animal models and human subjects suggests that the development of such a pro-neurodegenerative cellular environment can be accelerated or retarded by genetic and environmental factors. ${ }^{29,30}$ While the majority of dementia patients exhibit pathology commensurate with the severity of their cognitive impairment, there is often discordance between the type and magnitude of the histopathological abnormalities and cognitive function. At one extreme are individuals with abundant $A \beta$ pathology who are cognitively normal, and at the other extreme are those with extensive neuronal degeneration but relatively modest accumulation of proteopathic proteins. ${ }^{31,32}$ And so for each type of proteopathic alteration ( $A \beta$ plaques, $p$-Tau, a-synuclein aggregates, TDP-43 inclusions) any particular ILOD patient can be positioned somewhere within the distribution range of all ILOD patients (Figure 1). Assuming each of the different aggregation-prone proteins contributes to the dysfunction and degeneration of neurons in ILODs, then it follows that there are additional factors that determine whether or not neurons succumb to the cytotoxic action of the proteopathic protein(s). It should also be noted that a proteopathic protein may not be a critical factor in the mechanism of neuronal degeneration in some cases of ILOD; for example, the pathological landscape of HSA can be largely devoid of pathogenic protein aggregates. The remainder of this article considers the age-related cellular and molecular mechanisms that may render neurons vulnerable to ILOD, and how those mechanisms can be modified by environmental factors, with a focus on diet, exercise and intellectual challenges throughout the lifespan.

\section{NEURONAL VULNERABILITY IN ILOD CAN OCCUR UPSTREAM AND DOWNSTREAM OF PROTEOPATHIC PROTEINS}

Histopathological studies of the brains of cognitively normal octogenarians, nonagenarians and centenarians have shown that essentially all very old subjects exhibit one or more neuropathological features, with many having levels of $A \beta$ plaques and $p$-Tau sufficient for a diagnosis of $A D .^{31,32}$ On the other hand, some subjects may have only modest amounts of $A \beta$ plaques and $p$-Tau pathology and yet exhibit robust neuronal loss and cognitive impairment. These dissociations between levels of 'pathogenic proteins' and cognitive deficits strongly suggest that there are unknown factors that determine whether the neurons of any particular individual are resistant to or vulnerable to the accumulation of proteopathic proteins and/or are resistant to or vulnerable to the toxicity of the proteopathic proteins.

Considerable evidence suggests that synapse loss is a stronger predictor of cognitive impairment in ILOD than is any particular aggregated protein pathology. ${ }^{33-36}$ Knowledge of the qualitative and quantitative aspects of synapse physiology provides a framework for understanding why excitatory synapses may be the 'Achilles heel' of the neuronal networks that succumb in ILOD (and neurodegenerative disorders, in general). This topic has been reviewed in more detail elsewhere. ${ }^{37-40}$ Suffice it to say that excitatory (glutamatergic) synapses experience robust repetitive bouts of ionic, metabolic and oxidative stress during their normal activity throughout the life course. Synapse activation involves depolarization of the presynaptic terminal membrane, resulting in 
the opening of voltage-gated $\mathrm{Na}^{+}$and $\mathrm{Ca}^{2+}$ channels, and $\mathrm{Ca}^{2+}$ influx, which triggers glutamate release from the presynaptic terminal. Glutamate activates postsynaptic ionotropic AMPA and $\mathrm{N}$-methyl-D-aspartate (NMDA) receptors, resulting in $\mathrm{Ca}^{2+}$ influx and activation of kinases and transcription factors that regulate various acute and long-term adaptive responses of the neuron. Excessive sustained activation of glutamate receptors can cause degeneration of the synapse and neuronal death by activating proteases, impairing mitochondrial function and promoting oxidative stress.

Early studies provided evidence that during the process of aggregation on the membrane of neurons and synapses $A \beta$ causes lipid peroxidation, which impairs the function of ion-motive ATPases, and glucose and glutamate transporters, destabilizes $\mathrm{Ca}^{2+}$ homeostasis, and renders the neurons vulnerable to excitotoxicity. ${ }^{41-44}$ Importantly, several adverse conditions that occur in the brain during normal aging and that are exacerbated in ILOD may increase the vulnerability of neurons to the toxic actions of $A \beta, p$-Tau, a-synuclein and TDP-43 (Figure 2). These conditions include impaired bioenergetics/mitochondrial function, oxidative stress, inflammation, and impaired proteasome- and autophagy-mediated removal of damaged proteins and organelles. ${ }^{45-50}$ In addition, reductions in neurotrophic factor support as the result of decreased expression of the trophic factors and/or impaired signaling downstream of the neurotrophic factor receptors occurs during brain aging and more so in ILOD. ${ }^{51}$ For example, reduced expression of brain-derived neurotrophic factor (BDNF) and impaired insulin/insulin-like growth factor signaling occurs in the hippocampus in aging and AD. ${ }^{51,52}$ Both BDNF and insulin-like growth factor 1 can protect neurons in experimental models of AD. ${ }^{53,54}$

Data suggest that aging and stress-related cellular energy deficits, excessive activation of glutamate receptors and oxidative stress contribute to the accumulation of $\mathrm{p}$-Tau and neurofibrillary degeneration. ${ }^{55,56}$ FTD-causing Tau mutations may promote neuronal degeneration by perturbing cellular $\mathrm{Ca}^{2+}$ regulation ${ }^{57}$ and impairing autophagy. ${ }^{58}$ Recent studies suggest that pathogenic forms of TDP-43 render neurons vulnerable to

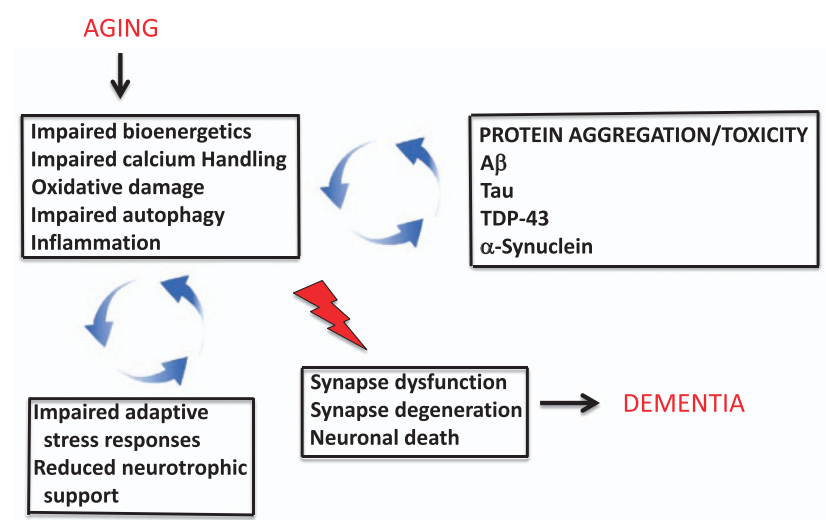

Figure 2. Generic age-related cellular stress and specific proteopathic abnormalities exert reciprocal cross-amplifying detrimental effects on synaptic plasticity and neuronal viability. During aging, neurons experience reduced energy availability (e.g., mitochondrial dysfunction and reduced glucose transport), increased levels of oxidative stress, perturbed cellular calcium homeostasis, impaired autophagy, and inflammation. The latter adverse changes are exacerbated by a reduced ability of neurons to respond adaptively to stress. The aggregation and associated neurotoxic activities of proteopathic proteins (A $\beta$, Tau, TDP-43 and $\alpha$-synuclein) are promoted by metabolic, oxidative and calcium-related stress and impaired autophagy/protein degradation. Thus, cross-amplifying neurodegenerative processes result in synapse dysfunction, degeneration and neuronal death, resulting in dementia. excitotoxicity $^{59}$ and mitochondrial dysfunction ${ }^{60,61}$ and that stimulation of autophagy can protect neurons against TDP-43 toxicity. ${ }^{62}$ Finally, a-synuclein pathology may result from and exacerbate neuronal oxidative stress, mitochondrial dysfunction and impaired proteasome function and autophagy. ${ }^{63,64}$ It is likely that the latter alterations first compromise synapse function, which, in turn, leads to neuronal degeneration. Indeed, it was shown that a-synuclein pathology can be lessened, and synaptic dysfunction and memory impairment can be reversed, by inhibiting a-synuclein expression in an inducible a-synuclein transgenic mouse model. ${ }^{65}$

Altogether, the available data from studies of human subjects and experimental models suggest that oxidative stress, bioenergetic deficits, cellular $\mathrm{Ca}^{2+}$ dysregulation, impaired autophagy and inflammatory glial reactions (1) occur in the brain during normal aging; (2) initiate and accelerate the accumulation of proteopathic proteins ( $A \beta, p-T a u, a-s y n u c l e i n$ and TDP-43) in ILOD; and (3) mediate the synaptotoxic and cell death-promoting effects of each of the different proteopathic proteins. This knowledge suggests that interventions that bolster neuronal bioenergetics, autophagy and defenses against oxidative and excitotoxic stress may forestall development of most, if not all, cases of ILOD.

\section{COMPROMISED ADAPTIVE CELLULAR STRESS RESPONSES AND ILOD}

The ability of neurons in the brain to cope with stress (bioenergetic, oxidative, ionic, proteotoxic) is diminished during aging. ${ }^{66-70}$ Although thousands of studies have documented age-related decrements in molecular mechanisms that promote neuronal plasticity and survival, most can be placed within one of a relatively few general categories of stress response pathways that include neurotrophic factor signaling; defense against oxidative stress; mitochondrial function; calcium homeostasis protein quality control; molecular waste disposal; and DNA repair.

\section{Neurotrophic factors}

Studies of postmortem brain tissue samples, and of animal and cell culture models, suggest that a decline in neurotrophic support contributes to the dysfunction and degeneration of neurons in ILODs. Among the neurotrophic factors that may be compromised in ILODs, BDNF is of particular interest because of its well-established fundamental roles in synaptic plasticity, learning and memory, and hippocampal neurogenesis. ${ }^{71}$ In human subjects levels of BDNF in the cerebrospinal fluid decrease during aging and are further reduced in subjects with poorer cognitive performance. ${ }^{72}$ Age-related reductions of BDNF expression in the hippocampus occur during normal aging in rodents, and further decrements in hippocampal BDNF levels have been reported to occur in animal models of AD. ${ }^{73,74}$ Moreover, when levels of BDNF are increased in the entorhinal cortex using a gene therapy approach, cognitive deficits can be reversed in rodent and nonhuman primate models of AD. ${ }^{75}$ BDNF deficiency is also implicated in the pathogenesis of PD, ${ }^{71}$ while roles for BDNF in HSA and LBD have yet to be investigated. BDNF may protect neurons against metabolic and oxidative stress by stimulating mitochondrial biogenesis, $^{76}$ and by upregulating antioxidant defenses. ${ }^{77}$

\section{Antioxidant defenses}

Superoxide dismutase 2 (SOD2) and heme oxygenase 1 are two antioxidant enzymes that decline in brain cells during aging. ${ }^{77,78}$ SOD2 protects neurons against decrements in energy availability and $A \beta$ toxicity, and experimental reduction of SOD2 levels accelerates the onset of cognitive deficits in APP mutant transgenic AD mice. ${ }^{79}$ Moreover, that SOD2 deficiency can trigger Tau hyperphosphorylation ${ }^{80}$ suggests a role for elevated mitochondrial oxidative stress in AD, FTD and other 'Tauopathies'. 
Healthy neurons respond to the oxidative stress triggered by excitatory synaptic activity by activating the transcription factors NF-KB and Nrf2, which, in turn induces the expression of SOD2 and heme oxygenase 1 , respectively. ${ }^{81,82}$ Another defense against oxidative stress that is adversely impacted in aging and $A D$ is the plasma membrane redox system, which includes the enzymes reduced form of nicotinamide adenine dinucleotide (NADH)-quinone oxidoreductase 1 (NQO1), NADH-ferrocyanide reductase, $\mathrm{NADH}$-coenzyme $\mathrm{Q} 10$ reductase and $\mathrm{NADH}$ cytochrome $c$ reductase. ${ }^{83,84}$

\section{Cellular bioenergetics}

Mitochondrial function generally declines during normal brain aging and to a greater extent in ILOD. ${ }^{85-87}$ Data suggest that electron transport chain proteins and proteins involved in the citric acid cycle are compromised in ILOD as a result of oxidative damage to the proteins and by damage to the mitochondrial DNA that encodes some of the electron transport chain proteins. ${ }^{88}$ Studies of patient brain tissue samples and of experimental models suggest that the alpha-ketoglutarate dehydrogenase complex of the citric acid cycle is adversely affected early in $A D .^{89}$ In PD, complex I of the electron transport chain appears particularly prone to dysfunction. ${ }^{86}$ Emerging findings, elaborated upon below, suggest that interventions that enhance mitochondrial bioenergetics can counteract the neurodegenerative process in multiple ILODs including AD, PD dementia and FTD. For example, bolstering cellular bioenergetics by administration of nicotinamide $^{90}$ or a ketone ester ${ }^{91}$ ameliorates learning and memory deficits in mouse models of AD. Moreover, a drug that opens mitochondrial potassium channels (diazoxide) can ameliorate cognitive defenses and lessen $A \beta$ and $p$-Tau pathologies in a mouse model of $A D .{ }^{92}$ The latter finding is particularly interesting in light of recent evidence that polymorphisms in the gene encoding a subunit of the $\mathrm{K}^{+}$channels activated by diazoxide may affect the risk of HSA. ${ }^{15,16}$

\section{Neuronal calcium handling}

The ability of neurons to efficiently control the disposition of $\mathrm{Ca}^{2+}$ among subcellular compartments is compromised during aging and may result in $\mathrm{Ca}^{2+}$ overload and excitotoxic degeneration of synapses. ${ }^{93,94}$ It is well known that neurons are susceptible to excitotoxic damage when their bioenergetics is compromised and when they are subjected to increased levels of oxidative stress or reduced levels of neurotrophic support. One of the approved treatments for $A D$, memantine, acts by reducing $\mathrm{Ca}^{2+}$ influx through the NMDA subtype of glutamate receptor. ${ }^{95}$ Importantly, mutations in genes that cause early-onset $A D$ (presenilin 1 and APP) and PD (a-synuclein and Parkin), and that may increase the risk of $A D(A p o E 4)$ and HSA (ABCC9), impair the ability of neurons to properly regulate $\mathrm{Ca}^{2+}$ and may thereby render the neurons vulnerable to $\mathrm{Ca}^{2+}$ overload-mediated cell death.,9,96,97 A better understanding of the pivotal molecular alterations that render neurons vulnerable to $\mathrm{Ca}^{2+}$ overload may suggest novel approaches for therapeutic interventions aimed at restoring cellular $\mathrm{Ca}^{2+}$ homeostasis.

\section{Molecular garbage disposal}

A robust alteration that occurs in neurons during aging that likely contributes to the accumulation of proteopathic proteins in ILOD is impaired autophagy and proteasome function. ${ }^{48,98}$ Intracellular accumulation of $A \beta$, $a$-synuclein and Tau may normally be prevented be targeting these proteins to the proteasome and/or lysosomes. Impaired ubiquitin-mediated proteasomal degradation of a-synuclein may result from age-related oxidative damage to proteasome proteins $^{99}$ or excessive production of a-synuclein. ${ }^{100}$ Impaired lysosome function is believed to contribute to the accumulation of dysfunctional mitochondria, which are normally degraded by 'mitophagy'. ${ }^{101}$ Interventions that enhance proteasome function and autophagy have been reported to counteract neuronal dysfunction and degeneration in experimental models of ILODs. For example, methylene blue enhances proteasomal degradation and improves cognitive function in a mouse model of $A D,{ }^{102}$ and methylene blue also enhances autophagy and thereby suppresses Tau pathology in models relevant to FTD. ${ }^{58}$ Dietary energy restriction (DER), which is known to stimulate autophagy, is neuroprotective in animal models of AD and PD (see ref. 30 for review). Thus, enhancement of protein quality control and removal of damaged proteins can counteract adverse conditions relevant to ILODs.

\section{DNA damage}

DNA damage in brain cells is caused predominately by free radicals and is increased during normal aging, and to a greater extent in $A D$ and presumably other ILODs. This accumulation of DNA damage results, in part, from impaired DNA repair, particularly base-excision repair. ${ }^{88}$ During aging there occurs an accumulation of damage to DNA in the nuclear genome and in mitochondria. A study of human subjects provided evidence that the regulatory elements of certain genes that encode proteins involved in synaptic plasticity and adaptive stress responses exhibit a predilection for DNA damage, resulting in a corresponding reduction in levels of expression of those genes. ${ }^{103}$ Studies of genetically modified mice have shown that deficiencies in several DNA repair enzymes increase the vulnerability of neurons to metabolic stress; examples include the base excision repair enzymes endonuclease VIII-like 1 and 7,8-dihydro-8-oxoguanine DNA glycosylase. ${ }^{104,105}$ In addition, expression of the enzyme DNA polymerase $\beta$ decreases in brain cells during normal aging, and experimental reduction of DNA polymerase $\beta$ expression triggers neuronal death and cognitive deficits in a mouse model of AD with $A \beta$ and $p$-Tau pathology. ${ }^{106}$ It was recently reported that neuronal DNA repair can be enhanced by activation of glutamate receptors and $\mathrm{BDNF}^{107,108}$ suggesting that age-related decrements in synaptic plasticity and neurotrophic support may contribute to increased neuronal DNA damage in ILOD.

\section{HOW MIGHT INTERMITTENT CHALLENGES BOLSTER NEURONAL RESISTANCE TO ILOD?}

In this section I summarize evidence that suggests it may be possible to forestall most cases of ILOD by enhancing the ability of neurons to mitigate the stressors involved in the neurodegenerative process, including metabolic, oxidative, ionic, proteotoxic and inflammatory stress. This can be accomplished by regular 'challenge-recovery cycles' in which neurons experience a mild stress (excitatory, metabolic and oxidative) during the challenge, followed by a rest/recovery period (Figure 3). For the following reasons, I focus on exercise, DER and regular engagement in intellectual challenges: (1) the evidence from animal studies that the latter three intermittent challenges enhance neuroplasticity and the resistance of neurons to injury and disease is compelling and conclusive; (2) the evidence from human studies is strong; (3) adaptive responses of the nervous system to exercise, energy restriction and intellectual challenges have been tested and refined during millions of years of evolution; (4) individuals concerned about their brain health can choose to incorporate these three challenges into their daily and weekly routines without concern for the kinds of adverse side effects common with drugs. For more thorough coverage of this topic, I refer the reader to recent reviews on exercise, energy restriction and intellectual challenges in brain health and disease resistance. ${ }^{30,109-111}$ 


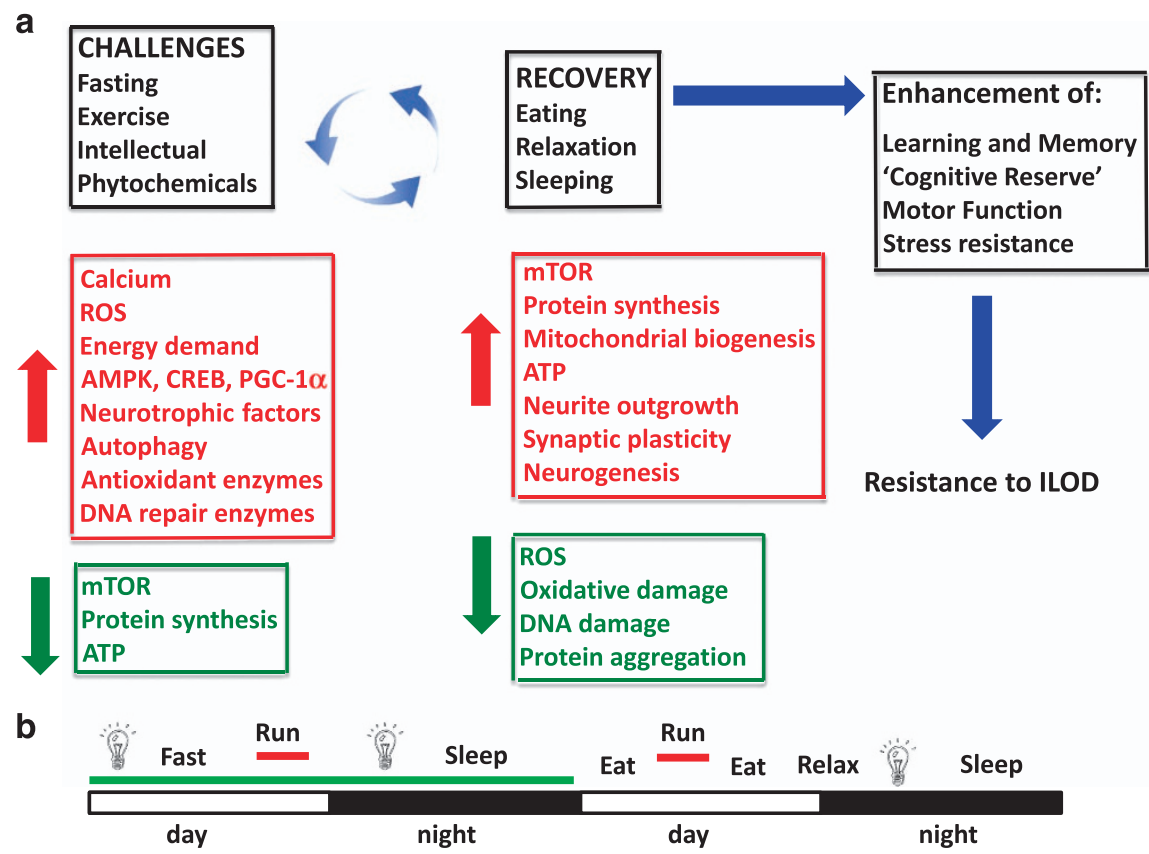

Figure 3. Intermittent bioenergetic challenges forestall ILOD by stimulating adaptive stress response pathways. (a) As with other species, humans evolved in environments where there was competition for food, mates and other resources. Accordingly, selection favored individuals whose brains functioned best when they were hungry, physically active and under stress. In response to the challenges (exercise, dietary energy restriction/fasting, intellectual challenges and consumption of noxious phytochemicals) neurons experience mild bioenergetic and oxidative stress. The neurons respond adaptively by activating signaling pathways that improve their ability to cope with more severe stress and resist disease. These neuroprotective pathways are triggered by calcium, reactive oxygen species (ROS) and increased energy demand, and involve kinases such as AMP-activated kinase (AMPK), and transcription factors such as cyclic AMP response element binding protein (CREB). The latter pathways increase autophagy, and induce the expression of genes encoding neurotrophic factors, antioxidant enzymes and DNA repair enzymes. During the challenges there is a reduction of mTOR (mammalian target of rapamycin) activity and protein synthesis. Once the challenge is over (e.g., food has been acquired) there is a recovery period that involves eating, relaxing and sleeping. During the recovery period mTOR activity, protein synthesis and mitochondrial biogenesis increase, and the growth of axons and dendrites, formation of new synapses and neurogenesis (the production of new neurons from stem cells) occur. Because of the adaptive stress responses induced during the challenge period levels of oxidative stress, DNA damage and protein aggregation are reduced. This model predicts that individuals who regularly engage in cycles of challenges and recovery periods during their adult life will exhibit optimal brain function and will be relatively resistant to the development of ILOD. (b) An example of a lifestyle that includes intermittent challenges as a means of optimizing brain health. In this case the person fasts (water or non-caloric beverages only) on the first day, while engaging in intellectual challenges (light bulb) and physical exercise (running). On the next day the subject eats several meals, runs, relaxes and engages in critical thinking.

Studies of human subjects have shown that regular physical exercise, particularly aerobic running, improves brain health as indicated by improved mood and enhanced cognitive function. ${ }^{112,113}$ Even in elderly subjects, exercise interventions can enhance cognitive performance and may preserve or increase gray and white matter volumes in some brain regions. ${ }^{114,115}$ Importantly, with regard to the main topic of the present article is evidence from human epidemiological data and studies of animal models suggesting that regular exercise can forestall ILOD and protein aggregation-related pathologies including $A \beta, p$-Tau and a-synuclein. ${ }^{116-118}$ Similarly, DER has been reported to ameliorate cognitive deficits and lessen accumulation and/or neurotoxicity of $A \beta$ in animal models of AD. ${ }^{19-121}$ Environmental enrichment can also lessen $A \beta$ and Tau pathologies and improve cognitive function in transgenic mouse models of ILOD. ${ }^{122,123}$ With regard to human studies there is evidence that individuals who avoid weight gain and central adiposity in midlife, ${ }^{124,125}$ and those who regularly engage in intellectually challenging endeavors, ${ }^{126}$ are at reduced risk for ILOD. The question then becomes 'what are the molecular and cellular mechanisms by which DER, exercise and cognitively stimulating environments can counteract age-related cellular stress and disease processes involved in ILOD?'

DER can robustly increase both the average and maximum lifespan in a range of mammalian species $^{127,128}$ and can protect neurons against dysfunction and degeneration in animal models of AD, PD, Huntington's disease, stroke and epileptic seizures. $^{30,129-131}$ DER can also counteract the major age- and disease-related adverse conditions that may trigger and exacerbate ILOD, including oxidative stress, ${ }^{132-134}$ bioenergetic deficits, $^{135,136}$ excitotoxicity, ${ }^{129,137}$ inflammation ${ }^{30,138}$ and proteotoxic pathologies. ${ }^{130,131}$ Compared to DER, voluntary running wheel exercise has more modest effects on lifespan, ${ }^{139,140}$ and on markers of brain oxidative stress and inflammation. ${ }^{141-143}$ Similar to exercise, environmental enrichment has been reported to reduce brain oxidative stress and inflammation in animal models of ILOD. ${ }^{144,145}$

Neurotrophic factors produced in an activity-dependent and cellular energy status-responsive manner mediate adaptive neuroplastic responses to exercise, fasting and cognitive enrichment. The cellular responses to these challenges include long-term potentiation of synaptic transmission, dendritic spine formation and hippocampal neurogenesis. ${ }^{30}$ Exercise and cognitive challenges induce BDNF expression in the hippocampus and other brain regions. ${ }^{146-148}$ The evidence that BDNF plays critical roles in multiple beneficial effects of exercise and enriched environments on hippocampal plasticity in mice and rats is extensive. ${ }^{146-149}$ Whether BDNF is critical for protection against ILOD by exercise, DER and intellectual challenges remains to be established. However, a recent study provided evidence that a socially enriched environment can rescue memory deficits in a mouse model of AD by a BDNF-dependent mechanism. ${ }^{150}$ Some studies have reported that exercise can increase BDNF levels in 
the serum or plasma of human subjects, ${ }^{150}$ although the source of the circulating BDNF is unknown, and it is unclear whether there is a direct relationship between brain and blood BDNF levels. In addition to BDNF, insulin-like growth factor 1 mediates adaptive responses of the brain to exercise. Circulating insulin-like growth factor 1 can enter the brain and affect gene expression in ways that stimulate neurogenesis and angiogenesis, and enhance synaptic plasticity and cognitive function. ${ }^{151-153}$

Much as occurs in skeletal muscle cells in response to vigorous exercise, recent findings suggest that bioenergetic challenges increase the ability of neurons to generate ATP by stimulating mitochondrial biogenesis (the growth and division of mitochondria). During exercise, $\mathrm{Ca}^{2+}$ influx and reactive oxygen species activate adenosine monophosphate-activated kinase (AMPK) and the transcription factor peroxisome proliferator-activated receptor-gamma coactivator 1a (PGC-1a) in muscle cells. ${ }^{154}$ PGC-1a then induces the expression of multiple genes encoding proteins required for mitochondrial biogenesis. In one study, treadmill training resulted in increased levels of PGC-1a and mitochondrial DNA electron transport chain proteins in multiple brain regions of mice, suggesting an increase in mitochondrial biogenesis. ${ }^{155}$ Combining intermittent exercise with DER enhances BDNF production and increases dendritic spine density in normal and diabetic mice, ${ }^{142}$ although it is unclear if DER enhances the effects of exercise on neuronal mitochondrial biogenesis. However, recent findings suggest that BDNF may mediate mitochondrial biogenesis in response to exercise, DER and cognitive challenges. As evidence, BDNF induces PGC-1a expression and mitochondrial biogenesis in hippocampal neurons. ${ }^{76}$ Moreover, the ability of BDNF to promote synapse formation requires PGC-1a expression, ${ }^{76}$ suggesting the possibility that mitochondrial biogenesis plays a role in the stimulation of synapse formation by exercise and DER, and the protection of synapses against degeneration in ILOD.

While it is evident that regular engagement in cognitive challenges can promote maintenance of cognitive abilities during aging, an understanding of why intermittent exercise and DER also enhance cognitive abilities and may forestall ILOD is clarified by evolutionary considerations. Our human ancestors, and the species that preceded them, were regularly challenged with the necessity of acquiring sufficient food resources for survival and to support reproduction. Presumably, individuals whose cognitive abilities were best when they were hungry, physically fit, and actively exploring and encoding mental maps of their environment would have a survival advantage. Nervous systems that responded adaptively to the challenge of competing for limited amounts of food were those that were selected for. Arguably, many of the higher cognitive abilities that humans now possess evolved for the purpose of securing food. Indeed, it has been proposed that the great expansion of the visual and prefrontal cortices during hominid evolution was driven by the need to develop highly efficient foraging strategies. ${ }^{156,157}$ At a fundamental level, the essence of the superior capabilities of the human brain, including invention, imagination, efficient decision-making, creativity and language, is based on pattern processing. ${ }^{158} \mathrm{~A}$ prediction of the 'superior pattern-processing hypothesis' of human brain evolution is that physical exertion, DER and complex cognitive challenges enhance pattern- processing capability. Direct support for the latter prediction comes from recent studies showing that wheel running enhances spatial pattern separation in mice ${ }^{159}$ and that exercise improves cognitive function across a range of domains in human subjects. ${ }^{160,161}$ ILOD involves progressive deficits in pattern processing resulting from the degeneration of neurons that mediate pattern processing. It is therefore reasonable to conclude that the same challenges that shaped the evolution of the human brain over millions of years can also sustain brain structure and function during aging.

\section{FUTURE DIRECTIONS AND IMPLICATIONS FOR THE PREVENTION AND TREATMENT OF ILOD}

While drug companies, neurologists and many researchers who study neurodegenerative disorders emphasize the need to develop and prescribe drugs specific for prototypical ILODs (i.e., $A D, F T D, L B D, H S A)$, the findings reviewed above suggest that the mosaic nature of the molecular and cellular neuropathological landscape of ILODs is more amenable to interventions that stimulate multiple pathways that bolster neuronal plasticity and stress resistance. The advantages of prescriptions for intermittent challenges (exercise, DER and intellectual endeavors) are manifest and include (1) the fact that our brains (and bodies) evolved so as to benefit from the challenges; (2) the relative lack of any adverse side effects; and (3) little or no cost to the patient (Figure 3). The barriers to intermittent challenge-based interventions revolve mostly around the economic and political forces that prevent their implementation, namely the pharmaceutical, processed food and health-care industries. Put simply, the profits of the latter industries would suffer greatly if prescriptions for intermittent challenge-based lifestyles were widely implemented such that far fewer individuals developed chronic diseases including ILOD. Therefore, a major future direction for research on intermittent challenges that engage adaptive stress response pathways is to better understand the specific machinations of the pharmaceutical and food industries that have fostered the rising tide of populations that are encouraged to overeat, and then to take drugs to treat the symptoms of the many ailments they develop.

Challenge-recovery cycles and the term hormesis describe the temporal and quantitative features of intermittent challenges that bolster brain health and resistance to ILOD. The molecular and cellular changes that occur in brain cells during the challenge (exercise, DER and cognitive challenges) and recovery (rest, eating, sleeping) periods are beginning to be understood (Figure 3a). During the challenge, neuronal activity and energy demand increase, and kinases (e.g., CaMKII and AMPK) and transcription factors (e.g., CREB and PGC-1a) are activated. As a consequence, the expression of genes encoding proteins involving autophagy, free radical metabolism and DNA repair is increased. This challenge places the cells in a 'preservation mode' in which mammalian target of rapamycin activity and overall protein synthesis are reduced, while pathways that bolster stress resistance are engaged. During the recovery period, protein synthesis increases, mitochondrial biogenesis occurs, and neurite outgrowth, synapse formation and neurogenesis occur. In the absence of challenges (i.e., a 'couch potato' lifestyle), the pathways normally activated by the challenges are downregulated, resulting in the accumulation of 'molecular toxic waste' including aggregated $A \beta, p-T a u, T D P-43$ and $a-$ synuclein, and dysfunctional mitochondria. Future research on the effects of challengerecovery cycles should include (1) expanding and refining an understanding of the molecular and cellular responses of brain cells to different patterns and intensities of challenges, and the impact of individual and combined challenges on functional outcomes in animal models relevant to ILODs; (2) randomized controlled trials to establish the effects of intermittent challenges on brain function and chemistry in healthy subjects, individuals at risk for ILOD, and individuals in the early symptomatic stage of ILOD; and (3) development and implementation of specific prescriptions for intermittent challenge routines to promote and sustain brain health during aging (e.g., Figure $3 b$ ).

Hormesis occurs when transient exposure of a cell or organism to a low to moderate level of an agent or condition (e.g., ingestion of a chemical, high temperature, exercise, food deprivation) induces an adaptive/beneficial response, while exposure to higher and/or sustained levels of the agent or condition results in detrimental effects on the cell or organism. ${ }^{162-164}$ Thus, a biphasic dose-response curve is a defining feature of hormesis. In addition 
to the evidence suggesting that exercise, DER and intellectual challenges may forestall ILOD by hormesis-based mechanisms, it has been shown that chemical challenges can activate adaptive stress response pathways and protect neurons in models relevant to ILOD. Indeed, emerging findings suggest that some chemicals in fruits and vegetables are 'toxins' from the perspective of plant evolution-they are noxious phytochemicals that function as natural pesticides/antifeedants. Examples of such neuroprotective 'hormetic phytochemicals' include sulforaphane, curcumin, epicatechins and resveratrol. ${ }^{165}$ Considerable further basic and translational research will be required to determine if and to what extent such phytochemicals, or man-made drugs that activate hormetic pathways, can counteract the pathological cascades believed to occur in ILOD. Nevertheless, a broader appreciation of the potential for approaches that engage intrinsic pathways that bolster neuroplasticity and stress resistance may help accelerate the development of viable prophylactic and treatment approaches to halt and reverse the emerging ILOD crisis.

\section{ACKNOWLEDGEMENTS}

This work was supported by the Intramural Research Program of the National Institute on Aging. The author declares that no funding was received.

\section{COMPETING INTERESTS}

The author declares no conflict of interest.

\section{REFERENCES}

1 Dowling NM, Tomaszewski Farias S, Reed BR, Sonnen JA, Strauss ME, Schneider JA et al. Neuropathological associates of multiple cognitive functions in two community-based cohorts of older adults. J Int Neuropsychol Soc 2011; 17: 602-614.

2 Cholerton B, Larson EB, Baker LD, Craft S, Crane PK, Millard SP et al. Neuropathologic correlates of cognition in a population-based sample. $J$ Alzheimers Dis 2013; 36: 699-709.

3 Wilson RS, Yu L, Trojanowski JQ, Chen EY, Boyle PA, Bennett DA et al. TDP-43 pathology, cognitive decline, and dementia in old age. JAMA Neurol 2013; 70: 1418-1424.

4 Bertram L, Lill CM, Tanzi RE. The genetics of Alzheimer disease: back to the future. Neuron 2010; 68: 270-281.

5 Shinohara M, Fujioka S, Murray ME, Wojtas A, Baker M, Rovelet-Lecrux A et al. Regional distribution of synaptic markers and APP correlate with distinct clinicopathological features in sporadic and familial Alzheimer's disease. Brain 2014; 137: 1533-1549.

6 Hyman BT, Phelps CH, Beach TG, Bigio EH, Cairns NJ, Carrillo MC et al. Alzheimers Dement 2012; 8: 1-13.

7 Geddes JW, Tekirian TL, Soultanian NS, Ashford JW, Davis DG, Markesbery WR. Comparison of neuropathologic criteria for the diagnosis of Alzheimer's disease. Neurobiol Aging 1997; 18: S99-S105.

8 Bezprozvanny I, Mattson MP. Neuronal calcium mishandling and the pathogenesis of Alzheimer's disease. Trends Neurosci 2008; 31: 454-463.

9 Ghetti B, Oblak AL, Boeve BF, Johnson KA, Dickerson BC, Goedert M. Invited review: Frontotemporal dementia caused by microtubule-associated proteintau gene (MAPT) mutations: a chameleon for neuropathology and neuroimaging. Neuropathol Appl Neurobiol 2015; 41: 24-46.

10 Benajiba L, Le Ber I, Camuzat A, Lacoste M, Thomas-Anterion C, Couratier P et al. TARDBP mutations in motoneuron disease with frontotemporal lobar degeneration. Ann Neurol 2009; 65: 470-473.

11 Renton AE, Majounie E, Waite A, Simón-Sánchez J, Rollinson S, Gibbs JR et al. A hexanucleotide repeat expansion in C9ORF72 is the cause of chromosome 9p21 linked ALS-FTD. Neuron 2011; 72: 257-268.

12 Mori K, Weng SM, Arzberger T, May S, Rentzsch K, Kremmer E et al. The C9orf72 GGGGCC repeat is translated into aggregating dipeptide-repeat proteins in FTLD/ALS. Science 2013; 339: 1335-1338.

13 Nelson PT, Smith CD, Abner EL, Wilfred BJ, Wang WX, Neltner JH et al. Hippocampal sclerosis of aging, a prevalent and high-morbidity brain disease. Acta Neuropathol 2013; 126: 161-177.

14 Dickson DW, Baker M, Rademakers R. Common variant in GRN is a genetic risk factor for hippocampal sclerosis in the elderly. Neurodegener Dis 2010; 7: 170-174.
15 Nelson PT, Estus S, Abner EL, Parikh I, Malik M, Neltner JH et al. ABCC9 gene polymorphism is associated with hippocampal sclerosis of aging pathology. Acta Neuropathol 2014; 127: 825-843.

16 Nelson PT, Wang WX, Partch AB, Monsell SE, Valladares O, Ellingson SR et al. Reassessment of risk genotypes (GRN, TMEM106B, and ABCC9 variants) associated withhippocampal sclerosis of aging pathology. J Neuropathol Exp Neurol 2015; 74: 75-84.

17 Hanson JC, Lippa CF. Lewy body dementia. Int Rev Neurobiol 2009; 84: 215-228.

18 Ferencz B, Gerritsen L. Genetics and underlying pathology of dementia. Neuropsychol Rev 2015; 25: 113-124.

19 Jellinger KA. Neurobiology of cognitive impairment in Parkinson's disease. Expert Rev Neurother 2012; 12: 1451-1466.

20 Houlden $\mathrm{H}$, Singleton AB. The genetics and neuropathology of Parkinson's disease. Acta Neuropathol 2012; 124: 325-338.

21 Venderova K, Park DS. Programmed cell death in Parkinson's disease. Cold Spring Harb Perspect Med 2012; 2: pii: a009365.

22 Kovacs GG, Milenkovic I, Wöhrer A, Höftberger R, Gelpi E, Haberler C et al. NonAlzheimer neurodegenerative pathologies and their combinations are more frequent than commonly believed in the elderly brain: a community-based autopsy series. Acta Neuropathol 2013; 126: 365-384.

23 Josephs KA, Whitwell JL, Weigand SD, Murray ME, Tosakulwong N et al. TDP-43 is a key player in the clinical features associated with Alzheimer's disease. Acta Neuropathol 2014; 127: 811-824.

24 Neltner JH, Abner EL, Baker S, Schmitt FA, Kryscio RJ, Jicha GA et al. Arteriolosclerosis that affects multiple brain regions is linked to hippocampal sclerosis of ageing. Brain 2014; 137: 255-267.

25 Serrano-Pozo A, Qian J, Monsell SE, Blacker D, Gómez-Isla T, Betensky RA et al. Mild to moderate Alzheimer dementia with insufficient neuropathological changes. Ann Neurol 2014; 75: 597-601.

26 Aoki N, Murray ME, Ogaki K, Fujioka S, Rutherford NJ, Rademakers R et al. Hippocampal sclerosis in Lewy body disease is a TDP-43 proteinopathy similar to FTLD-TDP type A. Acta Neuropathol 2015; 129: 53-64.

27 Rosenberg CK, Pericak-Vance MA, Saunders AM, Gilbert JR, Gaskell PC, Hulette CM. Lewy body and Alzheimer pathology in a family with the amyloidbeta precursor protein APP717 gene mutation. Acta Neuropathol 2000; 100 145-152.

28 Snider BJ, Norton J, Coats MA, Chakraverty S, Hou CE, Jervis R et al. Novel presenilin 1 mutation (S170F) causing Alzheimer disease with Lewy bodies in the third decade of life. Arch Neurol 2005; 62: 1821-1830.

29 Mattson MP. Pathways towards and away from Alzheimer's disease. Nature 2004; 430: 631-639.

30 Mattson MP. Energy intake and exercise as determinants of brain health and vulnerability to injury and disease. Cell Metab 2012; 16: 706-722.

31 Driscoll I, Troncoso J. Asymptomatic Alzheimer's disease: a prodrome or a state of resilience? Curr Alzheimer Res 2011; 8: 330-335.

32 Nelson PT, Alafuzoff I, Bigio EH, Bouras C, Braak H, Cairns NJ et al. Correlation of Alzheimer disease neuropathologic changes with cognitive status: a review of the literature. J Neuropathol Exp Neurol 2012; 71: 362-381.

33 Robinson JL, Molina-Porcel L, Corrada MM, Raible K, Lee EB, Lee VM et al. Perforant path synaptic loss correlates with cognitive impairment and Alzheimer's disease in the oldest-old. Brain 2014; 137: 2578-2587.

34 Scheff SW, Neltner JH, Nelson PT. Is synaptic loss a unique hallmark of Alzheimer's disease? Biochem Pharmacol 2014; 88: 517-528.

35 Spires-Jones TL, Hyman BT. The intersection of amyloid beta and tau at synapses in Alzheimer's disease. Neuron 2014; 82: 756-771.

36 Collins RC, Dobkin BH, Choi DW. Selective vulnerability of the brain: new insights into the pathophysiology of stroke. Ann Intern Med 1989; 110 992-1000.

37 Mattson MP, Magnus T. Ageing and neuronal vulnerability. Nat Rev Neurosci 2006; 7: 278-294.

38 Gleichmann M, Chow VW, Mattson MP. Homeostatic disinhibition in the aging brain and Alzheimer's disease. J Alzheimers Dis 2011; 24: 15-24.

39 Gillingwater TH, Wishart TM. Mechanisms underlying synaptic vulnerability and degeneration in neurodegenerative disease. Neuropathol Appl Neurobiol 2013; 39: 320-334.

40 Mattson MP, Cheng B, Davis D, Bryant K, Lieberburg I, Rydel RE. beta-Amyloid peptides destabilize calcium homeostasis and render human cortical neurons vulnerable to excitotoxicity. J Neurosci 1992; 12: 376-389.

41 Mark RJ, Hensley K, Butterfield DA, Mattson MP. Amyloid beta-peptide impairs ion-motive ATPase activities: evidence for a role in loss of neuronal $\mathrm{Ca}^{2+}$ homeostasis and cell death. J Neurosci 1995; 15: 6239-6249.

42 Mark RJ, Pang Z, Geddes JW, Uchida K, Mattson MP. Amyloid beta-peptide impairs glucose transport in hippocampal and cortical neurons; involvement of membrane lipid peroxidation. J Neurosci 1997; 17: 1046-1054. 
43 Keller JN, Pang Z, Geddes JW, Begley JG, Germeyer A, Waeg G et al. Impairment of glucose and glutamate transport and induction of mitochondrial oxidative stress and dysfunction in synaptosomes by amyloid beta-peptide: role of the lipid peroxidation product 4-hydroxynonenal. J Neurochem 1997; 69: 273-284.

44 Koistinaho M, Kettunen MI, Goldsteins G, Keinänen R, Salminen A, Ort M et al. Beta-amyloid precursor protein transgenic mice that harbor diffuse $\mathrm{A}$ beta deposits but do not form plaques show increased ischemic vulnerability: role of inflammation. Proc Natl Acad Sci USA 2002; 99: 1610-1615.

45 Huang X, Moir RD, Tanzi RE, Bush Al, Rogers JT. Redox-active metals, oxidative stress, and Alzheimer's disease pathology. Ann N Y Acad Sci 2004; 1012: $153-163$

46 Fang F, Lue LF, Yan S, Xu H, Luddy JS, Chen D et al. RAGE-dependent signaling in microglia contributes to neuroinflammation, Abeta accumulation, and impaired learning/memory in a mouse model of Alzheimer's disease. FASEB $J$ 2010; 24: 1043-1055.

47 Harris $H$, Rubinsztein DC. Control of autophagy as a therapy for neurodegenerative disease. Nat Rev Neurol 2011; 8: 108-117.

48 Nixon RA. The role of autophagy in neurodegenerative disease. Nat Med 2013; 19: $983-997$.

49 Quiroz-Baez R, Flores-Domínguez D, Arias C. Synaptic aging is associated with mitochondrial dysfunction, reduced antioxidant contents and increased vulnerability to amyloid- $\beta$ toxicity. Curr Alzheimer Res 2013; 10: 324-331.

50 Phillips HS, Hains JM, Armanini M, Laramee GR, Johnson SA, Winslow JW. BDNF mRNA is decreased in the hippocampus of individuals with Alzheimer's disease. Neuron 1991; 7: 695-702

51 Talbot K, Wang HY, Kazi H, Han LY, Bakshi KP, Stucky A et al. Demonstrated brain insulin resistance in Alzheimer's disease patients is associated with IGF-1 resistance, IRS-1 dysregulation, and cognitive decline. J Clin Invest 2012; 122: 1316-1338.

52 Arancibia S, Silhol M, Moulière F, Meffre J, Höllinger I, Maurice T et al. Protective effect of BDNF against beta-amyloid induced neurotoxicity in vitro and in vivo in rats. Neurobiol Dis 2008; 31: 316-326.

53 Kitiyanant N, Kitiyanant Y, Svendsen CN, Thangnipon W. BDNF-, IGF-1- and GDNF-secreting human neural progenitor cells rescue amyloid $\beta$-induced toxicity in cultured rat septal neurons. Neurochem Res 2012; 37: 143-152.

54 Cheng B, Mattson MP. Glucose deprivation elicits neurofibrillary tangle-like antigenic changes in hippocampal neurons: prevention by NGF and bFGF. Exp Neurol 1992; 117: 114-123.

55 Horiguchi $\mathrm{T}$, Uryu K, Giasson BI, Ischiropoulos $\mathrm{H}$, LightFoot $\mathrm{R}$, Bellmann $\mathrm{C}$ et al. Nitration of tau protein is linked to neurodegeneration in tauopathies. Am Pathol 2003; 163: 1021-1031.

56 Mattson MP. Antigenic changes similar to those seen in neurofibrillary tangles are elicited by glutamate and $\mathrm{Ca} 2+$ influx in cultured hippocampal neurons. Neuron 1990; 4: 105-117.

57 Furukawa K, Wang Y, Yao PJ, Fu W, Mattson MP, Itoyama Y et al. Alteration in calcium channel properties is responsible for the neurotoxic action of a familial frontotemporal dementia tau mutation. J Neurochem 2003; 87: 427-436.

58 Congdon EE, Wu JW, Myeku N, Figueroa YH, Herman M, Marinec PS et al. Methylthionimium chloride (methylene blue) induces autophagy and attenuates tauopathy in vitro and in vivo. Autophagy 2012; 8: 609-622.

59 Tong J, Huang C, Bi F, Wu Q, Huang B, Liu X et al. Expression of ALS-linked TDP-43 mutant in astrocytes causes non-cell-autonomous motor neuron death in rats. $E M B O J$ J 2013; 32: 1917-1926.

60 Stribl C, Samara A, Trümbach D, Peis R, Neumann M, Fuchs H et al. Mitochondrial dysfunction and decrease in body weight of a transgenic knock-in mouse model for TDP-43. J Biol Chem 2014; 289: 10769-10784.

61 Wang W, Li L, Lin WL, Dickson DW, Petrucelli L, Zhang T et al. The ALS diseaseassociated mutant TDP-43 impairs mitochondrial dynamics and function in motor neurons. Hum Mol Genet 2013; 22: 4706-4719.

62 Wang IF, Guo BS, Liu YC, Wu CC, Yang CH, Tsai KJ et al. Autophagy activators rescue and alleviate pathogenesis of a mouse model with proteinopathies of the TAR DNA-binding protein 43. Proc Natl Acad Sci USA 2012; 109: 15024-15029.

63 Yao Z, Wood NW. Cell death pathways in Parkinson's disease: role of mitochondria. Antioxid Redox Signal 2009; 11: 2135-2149.

64 Dimant H, Ebrahimi-Fakhari D, McLean PJ. Molecular chaperones and cochaperones in Parkinson disease. Neuroscientist 2012; 18: 589-601.

65 Lim Y, Kehm VM, Lee EB, Soper JH, Li C, Trojanowski JQ et al. a-Syn suppression reverses synaptic and memory defects in a mouse model of dementia with Lewy bodies. J Neurosci 2011; 31: 10076-10087.

66 Epel ES, Lithgow GJ. Stress biology and aging mechanisms: toward understanding the deep connection between adaptation to stress and longevity. J Gerontol A Biol Sci Med Sci 2014; 69: S10-S16.

67 Haigis MC, Yankner BA. The aging stress response. Mol Cell 2010; 40: 333-344.
68 McEwen BS, Morrison JH. The brain on stress: vulnerability and plasticity of the prefrontal cortex over the life course. Neuron 2013; 79: 16-29.

69 Miller DB, O'Callaghan JP. Aging, stress and the hippocampus. Ageing Res Rev 2005; 4: 123-140.

70 Texel SJ, Mattson MP. Impaired adaptive cellular responses to oxidative stress and the pathogenesis of Alzheimer's disease. Antioxid Redox Signal 2011; 14: 1519-1534.

71 Rothman SM, Mattson MP. Activity-dependent, stress-responsive BDNF signaling and the quest for optimal brain health and resilience throughout the lifespan. Neuroscience 2013; 239: 228-240.

72 Li G, Peskind ER, Millard SP, Chi P, Sokal I, Yu CE et al. Cerebrospinal fluid concentration of brain-derived neurotrophic factor and cognitive function in non-demented subjects. PLoS One 2009; 4: e5424.

73 Calabrese F, Guidotti G, Racagni G, Riva MA. Reduced neuroplasticity in aged rats: a role for the neurotrophin brain-derived neurotrophic factor Neurobiol Aging 2013; 34: 2768-2776.

74 Sen $A$, Nelson TJ, Alkon DL. ApoE4 and A $B$ oligomers reduce BDNF expression via HDAC nuclear translocation. J Neurosci 2015; 35: 7538-7551.

75 Nagahara AH, Merrill DA, Coppola G, Tsukada S, Schroeder BE, Shaked GM et al. Neuroprotective effects of brain-derived neurotrophic factor in rodent and primate models of Alzheimer's disease. Nat Med 2009; 15: 331-337.

76 Cheng A, Wan R, Yang JL, Kamimura N, Son TG, Ouyang X et al. Involvement of PGC-1a in the formation and maintenance of neuronal dendritic spines. Nat Commun 2012; 3: 1250.

77 Arumugam TV, Phillips TM, Cheng A, Morrell CH, Mattson MP, Wan R. Age and energy intake interact to modify cell stress pathways and stroke outcome. Ann Neurol 2010; 67: 41-52.

78 Keller JN, Kindy MS, Holtsberg FW, St Clair DK, Yen HC, Germeyer A et al. Mitochondrial manganese superoxide dismutase prevents neural apoptosis and reduces ischemic brain injury: suppression of peroxynitrite production, lipid peroxidation, and mitochondrial dysfunction. J Neurosci 1998; 18: 687-697.

79 Esposito L, Raber J, Kekonius L, Yan F, Yu GQ, Bien-Ly N et al. Reduction in mitochondrial superoxide dismutase modulates Alzheimer's disease-like pathology and accelerates the onset of behavioral changes in human amyloid precursor protein transgenic mice. J Neurosci 2006; 26: 5167-5179.

80 Melov S, Adlard PA, Morten K, Johnson F, Golden TR, Hinerfeld D et al. Mitochondrial oxidative stress causes hyperphosphorylation of tau. PLoS One 2007; 2: e536.

81 Mattson MP, Meffert MK. Roles for NF-kappaB in nerve cell survival, plasticity, and disease. Cell Death Differ 2006; 13: 852-860.

82 Mazzuferi M, Kumar G, van Eyll J, Danis B, Foerch P, Kaminski RM. Nrf2 defense pathway: experimental evidence for its protective role in epilepsy. Ann Neurol 2013: 74: 560-568.

83 Hyun DH, Emerson SS, Jo DG, Mattson MP, de Cabo R. Calorie restriction upregulates the plasma membrane redox system in brain cells and suppresses oxidative stress during aging. Proc Natl Acad Sci USA 2006; 103: 19908-19912.

84 Hyun $\mathrm{DH}$, Mughal MR, Yang $\mathrm{H}$, Lee $\mathrm{JH}$, Ko EJ, Hunt ND et al. The plasma membrane redox system is impaired by amyloid $\beta$-peptide and in the hippocampus and cerebral cortex of 3xTgAD mice. Exp Neurol 2010; 225: 423-429.

85 Navarro A, Boveris A. The mitochondrial energy transduction system and the aging process. Am J Physiol Cell Physiol 2007; 292: C670-C686.

86 Mattson MP, Gleichmann M, Cheng A. Mitochondria in neuroplasticity and neurological disorders. Neuron 2008; 60: 748-766.

87 Martin LJ. Biology of mitochondria in neurodegenerative diseases. Prog Mol Biol Transl Sci 2012; 107: 355-415.

88 Yang $\mathrm{JL}$, Weissman L, Bohr VA, Mattson MP. Mitochondrial DNA damage and repair in neurodegenerative disorders. DNA Repair (Amst) 2008; 7: $1110-1120$

89 Gibson GE, Starkov A, Blass JP, Ratan RR, Beal MF. Cause and consequence: mitochondrial dysfunction initiates and propagates neuronal dysfunction, neuronal death and behavioral abnormalities in age-associated neurodegenerative diseases. Biochim Biophys Acta 2010; 1802: 122-134.

90 Green KN, Steffan JS, Martinez-Coria H, Sun X, Schreiber SS, Thompson LM et al. Nicotinamide restores cognition in Alzheimer's disease transgenic mice via a mechanism involving sirtuin inhibition and selective reduction of Thr231phosphotau. J Neurosci 2008; 28: 11500-11510.

91 Kashiwaya $\mathrm{Y}$, Bergman C, Lee JH, Wan R, King MT, Mughal MR et al. A ketone ester diet exhibits anxiolytic and cognition-sparing properties, and lessens amyloid and tau pathologies in a mouse model of Alzheimer's disease. Neurobiol Aging 2013; 34: 1530-1539.

92 Liu D, Pitta M, Lee JH, Ray B, Lahiri DK, Furukawa K et al. The KATP channel activator diazoxide ameliorates amyloid- $\beta$ and tau pathologies and improves memory in the 3xTgAD mouse model of Alzheimer's disease. J Alzheimers Dis 2010; 22: 443-457. 
93 Foster TC. Calcium homeostasis and modulation of synaptic plasticity in the aged brain. Aging Cell 2007; 6: 319-325.

94 Toescu EC, Verkhratsky A. Parameters of calcium homeostasis in normal neuronal ageing. J Anat 2000; 197: 563-569.

95 Lipton SA. The molecular basis of memantine action in Alzheimer's disease and other neurologic disorders: low-affinity, uncompetitive antagonism. Curr Alzheimer Res 2005; 2: 155-165.

96 Calì T, Ottolini D, Brini M. Calcium signaling in Parkinson's disease. Cell Tissue Res 2014; 357: 439-454.

97 Veinbergs I, Everson A, Sagara Y, Masliah E. Neurotoxic effects of apolipoprotein E4 are mediated via dysregulation of calcium homeostasis. J Neurosci Res 2002; 67: 379-387.

98 Zheng C, Geetha T, Babu JR. Failure of ubiquitin proteasome system: risk for neurodegenerative diseases. Neurodegener Dis 2014; 14: 161-175.

99 Alvarez-Castelao B, Goethals M, Vandekerckhove J, Castaño JG. Mechanism of cleavage of alpha-synuclein by the $20 \mathrm{~S}$ proteasome and modulation of its degradation by the RedOx state of the N-terminal methionines. Biochim Biophys Acta 2014; 1843: 352-365.

100 Singleton $A B$, Farrer $M$, Johnson J, Singleton A, Hague S, Kachergus J et al. alpha-Synuclein locus triplication causes Parkinson's disease. Science 2003; 302 841.

101 Karbowski M, Neutzner A. Neurodegeneration as a consequence of failed mitochondrial maintenance. Acta Neuropathol 2012; 123: 157-171.

102 Medina DX, Caccamo A, Oddo S. Methylene blue reduces A $\beta$ levels and rescues early cognitive deficit by increasing proteasome activity. Brain Pathol 2011; 21 140-149.

103 Lu T, Pan Y, Kao SY, Li C, Kohane I, Chan J et al. Gene regulation and DNA damage in the ageing human brain. Nature 2004; 429: 883-891.

104 Canugovi C, Yoon JS, Feldman NH, Croteau DL, Mattson MP, Bohr VA. Endonuclease VIII-like 1 (NEIL1) promotes short-term spatial memory retention and protects from ischemic stroke-induced brain dysfunction and death in mice. Proc Natl Acad Sci USA 2012; 109: 14948-14953.

105 Liu D, Croteau DL, Souza-Pinto N, Pitta M, Tian J, Wu C et al. Evidence that OGG1 glycosylase protects neurons against oxidative DNA damage and cell death under ischemic conditions. J Cereb Blood Flow Metab 2011; 31: 680-692.

106 Sykora P, Misiak M, Wang Y, Ghosh S, Leandro GS, Liu D et al. DNA polymerase $\beta$ deficiency leads to neurodegeneration and exacerbates Alzheimer disease phenotypes. Nucleic Acids Res 2015; 43: 943-959.

107 Yang JL, Lin YT, Chuang PC, Bohr VA, Mattson MP. BDNF and exercise enhance neuronal DNA repair by stimulating CREB-mediated production of apurinic/ apyrimidinic endonuclease 1. Neuromol Med 2014; 16: 161-174.

108 Yang JL, Tadokoro T, Keijzers G, Mattson MP, Bohr VA. Neurons efficiently repair glutamate-induced oxidative DNA damage by a process involving CREB mediated up-regulation of apurinic endonuclease 1. J Biol Chem 2010; 285: 28191-28199.

109 Stranahan AM, Mattson MP. Recruiting adaptive cellular stress responses for successful brain ageing. Nat Rev Neurosci 2012; 13: 209-216.

110 van Praag H, Fleshner M, Schwartz MW, Mattson MP. Exercise, energy intake, glucose homeostasis, and the brain. J Neurosci 2014; 34: 15139-15149.

111 Sale A, Berardi N, Maffei L. Enrich the environment to empower the brain. Trends Neurosci 2009; 32: 233-239.

112 Brené S, Bjørnebekk A, Aberg E, Mathé AA, Olson L, Werme M. Running is rewarding and antidepressive. Physiol Behav 2007; 92: 136-140.

113 Stein DJ, Collins M, Daniels W, Noakes TD, Zigmond M. Mind and muscle: the cognitive-affective neuroscience of exercise. CNS Spectr 2007; 12: 19-22.

114 Erickson KI, Voss MW, Prakash RS, Basak C, Szabo A, Chaddock L et al. Exercise training increases size of hippocampus and improves memory. Proc Natl Acad Sci USA 2011; 108: 3017-3022.

115 Voss MW, Heo S, Prakash RS, Erickson Kl, Alves $\mathrm{H}$, Chaddock L et al. The influence of aerobic fitness on cerebral white matter integrity and cognitive function in older adults: results of a one-year exercise intervention. Hum Brain Mapp 2013; 34: 2972-2985.

116 Dimatelis JJ, Hendricks S, Hsieh J, Vlok NM, Bugarith K, Daniels WM et al. Exercise partly reverses the effect of maternal separation on hippocampal proteins in 6-hydroxydopamine-lesioned rat brain. Exp Physiol 2013; 98 233-244.

117 Erickson Kl, Weinstein AM, Lopez OL. Physical activity, brain plasticity, and Alzheimer's disease. Arch Med Res 2012; 43: 615-621.

118 García-Mesa Y, López-Ramos JC, Giménez-Llort L, Revilla S, Guerra R, Gruart A et al. Physical exercise protects against Alzheimer's disease in 3xTg-AD mice. $J$ Alzheimers Dis 2011; 24: 421-454.

119 Halagappa VK, Guo Z, Pearson M, Matsuoka Y, Cutler RG, Laferla FM et al. Intermittent fasting and caloric restriction ameliorate age-related behavioral deficits in the triple-transgenic mouse model of Alzheimer's disease. Neurobiol Dis 2007; 26: 212-220.
120 Patel NV, Gordon MN, Connor KE, Good RA, Engelman RW, Mason J et al. Caloric restriction attenuates Abeta-deposition in Alzheimer transgenic models. Neurobiol Aging 2005; 26: 995-1000.

121 Wang J, Ho L, Qin W, Rocher AB, Seror I, Humala N et al. Caloric restriction attenuates beta-amyloid neuropathology in a mouse model of Alzheimer's disease. FASEB J 2005; 19: 659-661.

122 Lahiani-Cohen I, Lourbopoulos A, Haber E, Rozenstein-Tsalkovich L, Abramsky O, Grigoriadis $\mathrm{N}$ et al. Moderate environmental enrichment mitigates tauopathy in a neurofibrillary tangle mouse model. J Neuropathol Exp Neurol 2011; 70 610-621.

123 Maesako M, Uemura K, Kubota M, Kuzuya A, Sasaki K, Asada M et al. Environmental enrichment ameliorated high-fat diet-induced $A \beta$ deposition and memory deficit in APP transgenic mice. Neurobiol Aging 2012; 33, 1011 e11-e23.

124 Luchsinger JA, Cheng D, Tang MX, Schupf N, Mayeux R. Central obesity in the elderly is related to late-onset Alzheimer disease. Alzheimer Dis Assoc Disord 2012; 26: 101-105.

125 Xu WL, Atti AR, Gatz M, Pedersen NL, Johansson B, Fratiglioni L. Midlife over weight and obesity increase late-life dementia risk: a population-based twin study. Neurology 2011; 76: 1568-1574.

126 Meng X, D'Arcy C. Education and dementia in the context of the cognitive reserve hypothesis: a systematic review with meta-analyses and qualitative analyses. PLoS One 2012; 7: e38268.

127 Longo VD, Mattson MP. Fasting: molecular mechanisms and clinical applications. Cell Metab 2014; 19: 181-192.

128 Spindler SR. Caloric restriction: from soup to nuts. Ageing Res Rev 2010; 9: 324-353.

129 Bruce-Keller AJ, Umberger G, McFall R, Mattson MP. Food restriction reduces brain damage and improves behavioral outcome following excitotoxic and metabolic insults. Ann Neurol 1999; 45: 8-15.

130 Duan W, Guo Z, Jiang H, Ware M, Li XJ, Mattson MP. Dietary restriction normalizes glucose metabolism and BDNF levels, slows disease progression, and increases survival in huntingtin mutant mice. Proc Natl Acad Sci USA 2003; 100 : 2911-2916.

131 Griffioen KJ, Rothman SM, Ladenheim B, Wan R, Vranis N, Hutchison E et al. Dietary energy intake modifies brainstem autonomic dysfunction caused by mutant a-synuclein. Neurobiol Aging 2013; 34: 928-935.

132 Dubey A, Forster MJ, Lal H, Sohal RS. Effect of age and caloric intake on protein oxidation in different brain regions and on behavioral functions of the mouse. Arch Biochem Biophys 1996; 333: 189-197.

133 Johnson JB, Summer W, Cutler RG, Martin B, Hyun DH, Dixit VD et al. Alternate day calorie restriction improves clinical findings and reduces markers of oxidative stress and inflammation in overweight adults with moderate asthma. Free Radic Biol Med 2007; 42: 665-674.

134 Singh R, Lakhanpal D, Kumar S, Sharma S, Kataria H, Kaur M et al. Late-onse intermittent fasting dietary restriction as a potential intervention to retard ageassociated brain function impairments in male rats. Age (Dordr) 2012; 34 917-933.

135 Lin AL, Coman D, Jiang L, Rothman DL, Hyder F. Caloric restriction impedes agerelated decline of mitochondrial function and neuronal activity. J Cereb Blood Flow Metab 2014; 34: 1440-1443.

136 Maalouf M, Rho JM, Mattson MP. The neuroprotective properties of calorie restriction, the ketogenic diet, and ketone bodies. Brain Res Rev 2009; 59 293-315.

137 Youssef FF, Ramchandani J, Manswell S, McRae A. Adult-onset calorie restriction attenuates kainic acid excitotoxicity in the rat hippocampal slice. Neurosci Let 2008; 431: 118-122.

138 Ugochukwu NH, Mukes JD, Figgers CL. Ameliorative effects of dietary caloric restriction on oxidative stress and inflammation in the brain of streptozotocininduced diabetic rats. Clin Chim Acta 2006; 370: 165-173.

139 Goodrick CL. Effects of long-term voluntary wheel exercise on male and female Wistar rats. I. Longevity, body weight, and metabolic rate. Gerontology 1980; 26: 22-33.

140 Holloszy JO, Schechtman KB. Interaction between exercise and food restriction: effects on longevity of male rats. J Appl Physiol (1985) 1991; 70 1529-1535.

141 Parachikova A, Nichol KE, Cotman CW. Short-term exercise in aged Tg2576 mice alters neuroinflammation and improves cognition. Neurobiol Dis 2008; 30 : 121-129.

142 Stranahan AM, Lee K, Martin B, Maudsley S, Golden E, Cutler RG et al. Voluntary exercise and caloric restriction enhance hippocampal dendritic spine density and BDNF levels in diabetic mice. Hippocampus 2009; 19: 951-961.

143 Stranahan AM, Lee K, Becker KG, Zhang Y, Maudsley S, Martin B et al. Hippocampal gene expression patterns underlying the enhancement of memory by running in aged mice. Neurobiol Aging 2010; 31: 1937-1949. 
144 Herring A, Blome M, Ambrée O, Sachser N, Paulus W, Keyvani K. Reduction of cerebral oxidative stress following environmental enrichmentin mice with Alzheimer-like pathology. Brain Pathol 2010; 20: 166-175.

145 Herring A, Lewejohann L, Panzer AL, Donath A, Kröll O, Sachser N et al. Preventive and therapeutic types of environmental enrichment counteract beta amyloid pathology by different molecular mechanisms. Neurobiol Dis 2011; 42: 530-538.

146 Kesslak JP, So V, Choi J, Cotman CW, Gomez-Pinilla F. Learning upregulates brain-derived neurotrophic factor messenger ribonucleic acid: a mechanism to facilitate encoding and circuit maintenance? Behav Neurosci 1998; 112: 1012-1019.

147 Oliff HS, Berchtold NC, Isackson P, Cotman CW. Exercise-induced regulation of brain-derived neurotrophic factor (BDNF) transcripts in the rat hippocampus. Brain Res Mol Brain Res 1998; 61: 147-153.

148 Llorens-Martín M, Torres-Alemán I, Trejo JL. Growth factors as mediators of exercise actions on the brain. Neuromol Med 2008; 10: 99-107.

149 Hsiao $\mathrm{YH}$, Hung HC, Chen SH, Gean PW. Social interaction rescues memory deficit in an animal model of Alzheimer's disease by increasing BDNF-dependent hippocampal neurogenesis. J Neurosci 2014; 34: 16207-16219.

150 Voss MW, Erickson Kl, Prakash RS, Chaddock L, Kim JS, Alves $\mathrm{H}$ et al. Neurobiological markers of exercise-related brain plasticity in older adults. Brain Behav Immun 2013; 28: 90-99.

151 Sonntag WE, Ramsey M, Carter CS. Growth hormone and insulin-like growth factor-1 (IGF-1) and their influence on cognitive aging. Ageing Res Rev 2005; 4 : 195-212.

152 Trejo JL, Carro E, Lopez-Lopez C, Torres-Aleman I. Role of serum insulin-like growth factor I in mammalian brain aging. Growth Horm IGF Res 2004; 14 Suppl A: S39-S43.

153 Yan H, Mitschelen M, Bixler GV, Brucklacher RM, Farley JA, Han S et al. Circulating IGF1 regulates hippocampal IGF1 levels and brain gene expression during adolescence . J Endocrinol 2011; 211: 27-37.

154 Holloszy JO. Regulation of mitochondrial biogenesis and GLUT4 expression by exercise. Compr Physiol 2011; 1: 921-940.

155 Steiner JL, Murphy EA, McClellan JL, Carmichael MD, Davis JM. Exercise training increases mitochondrial biogenesis in the brain. J Appl Physiol (1985) 2011; 111: 1066-1071.
156 Passingham RE, Wise SP. The Neurobiology of the Prefrontal Cortex: Anatomy, Evolution and the Origin of Insight. Oxford University Press: Oxford, UK, 2012.

157 Silver MA, Kastner S. Topographic maps in human frontal and parietal cortex. Trends Cogn Sci 2009; 13: 488-495.

158 Mattson MP. Superior pattern processing is the essence of the evolved human brain. Front Neurosci 2014; 8: 265.

159 Creer DJ, Romberg C, Saksida LM, van Praag H, Bussey TJ. Running enhances spatial pattern separation in mice. Proc Natl Acad Sci USA 2010; 107: 2367-2372.

160 Bielak AA, Cherbuin N, Bunce D, Anstey KJ. Preserved differentiation between physical activity and cognitive performance across young, middle, and older adulthood over 8 years. J Gerontol B Psychol Sci Soc Sci 2014; 69: 523-532.

161 Nouchi R, Taki Y, Takeuchi H, Sekiguchi A, Hashizume H, Nozawa T et al. Four weeks of combination exercise training improved executive functions, episodic memory, and processing speed in healthy elderly people: evidence from a randomized controlled trial. Age (Dordr) 2014; 36: 787-799.

162 Calabrese EJ, Bachmann KA, Bailer AJ, Bolger PM, Borak J, Cai L et al. Biological stress response terminology: integrating the concepts of adaptive response and preconditioning stress within a hormetic dose-response framework. Toxicol Appl Pharmacol 2007; 222: 122-128.

163 Rattan Sl. Hormesis in aging. Ageing Res Rev 2008; 7: 63-78.

164 Calabrese EJ, Mattson MP. Hormesis provides a generalized quantitative estimate of biological plasticity. J Cell Commun Signal 2011; 5: 25-38.

165 Lee J, Jo DG, Park D, Chung HY, Mattson MP. Adaptive cellular stress pathways as therapeutic targets of dietary phytochemicals: focus on the nervous system. Pharmacol Rev 2014; 66: 815-868.

\section{(c) (1)}

This work is licensed under a Creative Commons Attribution 4.0 International License. The images or other third party material in this article are included in the article's Creative Commons license, unless indicated otherwise in the credit line; if the material is not included under the Creative Commons license, users will need to obtain permission from the license holder to reproduce the material. To view a copy of this license, visit http://creativecommons.org/licenses/ by/4.0/ 